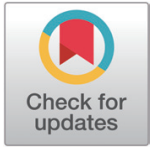

Received: Dec 14, 2021

Revised: Jan 7, 2022

Accepted: Jan 8, 2022

$\#_{\text {These authors contributed equally to }}$ this work.

${ }^{*}$ Corresponding author Abdolreza Hosseindoust College of Animal Life Sciences, Kangwon National University, Chuncheon 24341, Korea.

Tel: +82-33-250-8616

E-mail: Hosseindoust@kangwon.ac.kr

ByungJo Chae

College of Animal Life Sciences,

Kangwon National University,

Chuncheon 24341, Korea.

Tel: +82-33-250-8616

E-mail: bjchae@kangwon.ac.kr

Copyright $\odot 2022$ Korean Society of Animal Sciences and Technology. This is an Open Access article distributed under the terms of the Creative Commons Attribution Non-Commercial License (http:// creativecommons.org/licenses/by$\mathrm{nc} / 4.0 /$ ) which permits unrestricted non-commercial use, distribution, and reproduction in any medium, provided the original work is properly cited.

ORCID

TaeGyun Kim

https://orcid.org/0000-0002-9772-080X

MinJu Kim

https://orcid.org/0000-0001-6950-0458

\section{Supplementation of nano-zinc in lower doses as an alternative to pharmacological doses of $\mathrm{ZnO}$ in weanling pigs}

\author{
TaeGyun Kim ${ }^{1 \#}$, MinJu Kim" ${ }^{2 \#}$, JunHyung Lee ${ }^{3}$, Joseph Moturi ${ }^{1}$, \\ SangHun $\mathrm{Ha}^{1}$, Habeeb Tajudeen ${ }^{1}$, JunYoung Mun ${ }^{1}$, Abdolreza Hosseindoust ${ }^{1 *}$ \\ and ByungJo Chae ${ }^{1 *}$ \\ ${ }^{1}$ College of Animal Life Sciences, Kangwon National University, Chuncheon 24341, Korea \\ ${ }^{2}$ Centre for Nutrition and Food Sciences, Queensland Alliance for Agriculture and Food Innovation, The \\ University of Queensland, Queensland 4072, Australia \\ ${ }^{3}$ Department of Animal Biosciences, University of Guelph, Guelph, Ontario N1G 2W1, Canada
}

\begin{abstract}
A set of studies was performed to determine the influence of dietary $\mathrm{ZnO}$ concentration and source during two phases (days 0 to 14 and days 15 to 28). Experiment 1: 168 weaned piglets were allocated to four treatment groups in six replicates. The treatments included a basal diet without $\mathrm{ZnO}$ supplementation (control), 2,500 mg ZnO/kg (In2500), $500 \mathrm{mg}$ nano-ZnO/ $\mathrm{kg}$ (N500), and $150 \mathrm{mg}$ nano-ZnO/kg (N150). Experiment 2: 168 weaned piglets were divided into three treatment groups with eight replicates. The treatments included control, In2500, $\mathrm{N} 300$, and $150 \mathrm{mg}$ nano-ZnO/kg (N150). An in vitro trial showed that the growth of Listeria monocytogenes, Escherichia coli, and Salmonella typhimurium was inhibited when exposed to 300 and $500 \mathrm{ppm}$ of $\mathrm{ZnO}$ after $24 \mathrm{~h}$ of incubation. In experiment 1, the average daily gain (ADG) by the pigs was improved in the N500 and IN2500 treatment groups. Colonization of coliforms and Clostridium spp. significantly decreased in the pigs fed the N500 and IN2500 diets in phase 1. The total plasma antioxidant capacity was greater in the IN2500 and N500 treatment groups than in the control. Superoxide dismutase (SOD) activity was greater in pigs fed the IN2500 (phase 1) or the IN2500 and N500 (phase 2) diets than in the control and N150 treatment group. In experiment 2, pigs in the N300 treatment group showed a higher ADG and lower fecal score colonization of coliforms and Clostridium spp. compared with those in the N150 treatment group. In conclusion, nano-ZnO at a dose of $300 \mathrm{ppm}$ showed the same growth as the pharmacological dose of $\mathrm{Zn}$. This provides an option to the pharmacological dose.
\end{abstract}

Keywords: Antioxidant, Weanling pigs, Stress, ZnO, Superoxide dismutase, Microbiota

\section{INTRODUCTION}

Weaning is the most stressful time in a pig's life in modern swine farming and often causes diarrheic 
JunHyung Lee

https://orcid.org/0000-0002-7937-7817

Joseph Moturi

https://orcid.org/0000-0002-0626-0255

SangHun $\mathrm{Ha}$

https://orcid.org/0000-0003-3779-1144

Habeeb Tajudeen

https://orcid.org/0000-0002-5623-3175

JunYoung Mun

https://orcid.org/0000-0002-3075-7157

Abdolreza Hosseindoust

https://orcid.org/0000-0001-9191-0613

ByungJo Chae

https://orcid.org/0000-0002-8570-698X

\section{Competing interests}

No potential conflict of interest relevant to

this article was reported.

\section{Funding sources}

This work was supported by Korea Institute of Planning and Evaluation for Technology in Food, Agriculture, Forestry and Fisheries (IPET) through Agri-Bio industry Technology Development Program, funded by Ministry of Agriculture, Food and Rural Affairs (MAFRA) (No. 116073-03-2-CG000).

\section{Acknowledgements}

Not applicable.

Availability of data and material Upon reasonable request, the datasets of this study can be available from the corresponding author.

\section{Authors' contributions}

Conceptualization: Hosseindoust A, Chae BJ. Data curation: Kim TG, Moturi J.

Formal analysis: Kim MJ.

Methodology: Kim MJ, Tajudeen H.

Software: Kim TG, Ha SH, Hosseindoust A.

Validation: Lee JH, Moturi J.

Investigation: Kim TG, Mun JY.

Writing - original draft: Kim TG, Kim MJ, Lee JH, Moturi J, Ha SH, Tajudeen H, Mun JY, Hosseindoust A, Chae BJ.

Ethics approval and consent to participate The project underwent proper ethical standards and the experiments (KW-2105036 ) were approved by the Institutional Animal Care and Use Committee of Kangwon National University, Chuncheon, Korea. syndrome and growth depression [1-3]. At weaning, pigs are subjected to multiple stressors, including sudden dietary and environmental changes, that induce intestinal inflammation and unstable intestinal microbial communities $[1,2,4]$. The change from highly digestible milk to less digestible solid feed causes behavioral changes and intestinal infections, mostly because of coliform overgrowth [5,6], and is responsible for the $17 \%$ mortality rate of piglets in Europe [7]. The decreased feed intake and structural changes in the intestine influence the absorptive potential of nutrients through enterocytes, which may affect the growth rate [8,9]. Since the 2006 ban on antibiotics growth promoters by the European Union, research has focused on finding non-antibiotic supplements with antimicrobial potential to support gut health and weight gain of weaned pigs [10,11]. Among the alternatives, the pharmacological doses of $\mathrm{ZnO}(2,500$ and $3,000 \mathrm{mg} \mathrm{Zn} / \mathrm{kg}$ ) have been extensively used in the diets of weaning pigs for therapeutic purposes [12-14]. However, environmental concerns have encouraged several countries, including Korea and those in the European Union [15], to legislate strict rules limiting the use of $\mathrm{ZnO}$. The urgent challenge is to develop an alternative strategy to prevent post-weaning diarrhea because the supplementation with pharmacological $\mathrm{ZnO}$ will be phased out by June 2022 .

The extent to which an element is absorbed during digestion determines bioavailability $[16,17]$. In recent years, the common form of $\mathrm{ZnO}$ has been used routinely in piglet diets; however, the low biological potential of $\mathrm{ZnO}$ increased its supplementation level to 25 to 30 times more than the growth requirement. Nano techniques have been extensively used in the food and pharmaceutical industry to produce nano-sized particles with greater biological activity than conventional sources owing to the increased surface area [18]. The nano mineral particle sizes are in the range of 1 to 100 $\mathrm{nm}$; however, it is influenced by the molecular size and source of the minerals [18]. The decreased particle size of minerals correlates with their bioavailability $[13,19,20]$. Apart from the size of the nanoparticles, the nano process directly influences the biochemical properties of the elements. Hotmelt extrusion (HME) is among the most practical processes in the pharmaceutical field [18]. This method is based on mechanical shear and the polymer matrix to balance the mixing process at high temperatures to solubilize ingredients homogeneously $[18,20,21]$. The source and ratio of polymers determine the rate of aggregation and possibly the quality of the product. Our previous studies confirmed that the HME production process could be used as an environmentally friendly method in the animal feed industry to reduce trace mineral excretion $[16,22]$. Considering the importance of avoiding the pharmacological use of $\mathrm{ZnO}$ in the near future, the results of the current study may be a new hope to overcome this critical challenge. Therefore, the aim was to determine the effects of $\mathrm{ZnO}$ and nano- $\mathrm{ZnO}$ sources on body weight gain, nutrient digestibility, intestinal microbiota, gut integrity, and oxidative stress in weanling pigs.

\section{MATERIALS AND METHODS}

The protocol for this study was approved by Kangwon National University (Institute of Animal Care and Use Committee).

\section{Animals and experimental design}

The experimental farm of Kangwon National University, located in Chuncheon, Korea, was used to conduct this trial (Approval No: KW-210503-6). The experimental diets were balanced to meet or exceed nutritional requirements (Table 1) of swine nutrient specification except for $\mathrm{Zn}$ [23]. Experiment 1: A total of 168 weanling pigs (Landrace $\times$ Yorkshire $\times$ Duroc, $21 \pm 1 \mathrm{~d}$ old; body weight $[\mathrm{BW}] 6.81 \pm 1.06 \mathrm{~kg}$ ) were randomly distributed among the treatments based on a completely randomized design (CRD) according to initial BW. There were four treatments, 
Table 1. Formulation and chemical compositions of basal diets (as-fed basis)

\begin{tabular}{|c|c|c|}
\hline Item & $\begin{array}{l}\text { Phase } 1 \\
\text { (d 0-14) }\end{array}$ & $\begin{array}{c}\text { Phase 2 } \\
\text { (d 15-28) }\end{array}$ \\
\hline Ingredients (\%) & 100.00 & 100.00 \\
\hline Corn & 37.78 & 49.83 \\
\hline Soybean meal ( $48 \%$ of $\mathrm{CP})$ & 10.14 & 12.75 \\
\hline Oats-dehulled & 5.00 & 5.00 \\
\hline Whey powder & 15.00 & 10.00 \\
\hline Wheat bran & 3.50 & 4.00 \\
\hline Fish meal & 4.00 & 4.00 \\
\hline SDPP & 2.00 & \\
\hline Soy oil & 3.00 & 3.00 \\
\hline Soy hull & 2.00 & \\
\hline Biscuit byproduct & 3.00 & 2.00 \\
\hline Sucrose & 4.00 & 4.00 \\
\hline Lactose & 5.10 & \\
\hline Limestone & 1.25 & 1.25 \\
\hline MCP & 0.97 & 1.12 \\
\hline Salt & 0.20 & 0.25 \\
\hline L-Lysine $(78.0 \%)$ & 0.98 & 0.84 \\
\hline DL-Methionine (99\%) & 0.42 & 0.34 \\
\hline Trypsin (10\%) & 0.10 & 0.10 \\
\hline Threonine (99\%) & 0.41 & 0.37 \\
\hline Vitamin premix ${ }^{1)}$ & 0.15 & 0.15 \\
\hline Mineral premix & 0.20 & 0.20 \\
\hline Choline & 0.10 & 0.10 \\
\hline Enzymes & 0.05 & 0.05 \\
\hline Organic acid & 0.30 & 0.30 \\
\hline Mold inhibitor & 0.15 & 0.15 \\
\hline Probiotic & 0.20 & 0.20 \\
\hline \multicolumn{3}{|l|}{ Chemical composition (\%) } \\
\hline ME (kcal/kg) & 3,400 & 3,477 \\
\hline $\mathrm{CP}$ & 17.0 & 16.5 \\
\hline $\mathrm{Ca}$ & 0.85 & 0.85 \\
\hline Av. $P$ & 0.45 & 0.43 \\
\hline Lys & 1.70 & 1.50 \\
\hline Met+Cys & 0.96 & 0.85 \\
\hline Thr & 1.05 & 0.95 \\
\hline Trp & 0.28 & 0.25 \\
\hline
\end{tabular}

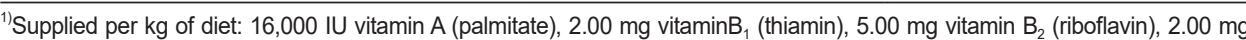
vitamin $B_{6}$ (pyridoxine), $0.03 \mathrm{mg}$ vitamin $B_{12}$ (cyanocobalamin), $25.00 \mathrm{mg}$ niacin, $0.40 \mathrm{mg}$ folic acid, $0.05 \mathrm{mg}$ biotin, $5.00 \mathrm{mg}$ ethoxyquin, 2,000 IU vitamin $\mathrm{D}_{3}$ (cholecalciferol), $75.00 \mathrm{mg}$ vitamin $\mathrm{E}$ (dl-a-tocopheryl acetate), $2.00 \mathrm{mg}$ vitamin $\mathrm{K}_{3}$ (menadione). ${ }^{2}$ Supplied per kg of diet: $100 \mathrm{mg} \mathrm{Fe}, 6 \mathrm{mg} \mathrm{Cu}, 4 \mathrm{mg} \mathrm{Mn}, 0.3 \mathrm{mg} \mathrm{Se}, 0.14 \mathrm{mg} \mathrm{I,} 0.25 \mathrm{mg}$ Co.

$\mathrm{CP}$, crude protein; SDPP, spray-dried porcine plasma; MCP, monocalcium phosphate; Lys, lysine; Met, methionine; Cys, cysteine; Thr, threonine; Trp, tryptophan.

six replicates, and seven pigs per replicate. The treatments were as follows: basal diet without $\mathrm{Zn}$ supplementation (control), 2,500 mg ZnO/kg (In2500), $500 \mathrm{mg}$ nano-ZnO/kg (N500), and 150 $\mathrm{mg}$ nano- $\mathrm{ZnO} / \mathrm{kg}$ (N150). The experiment was divided into two phases, from days 0 to 14 (phase 
1) and days 15 to 28 (phase 2). Experiment 2: A total of 168 weaned piglets (Yorkshire $\times$ Landrace $\times$ Duroc, $21 \pm 1 \mathrm{~d}$ old; BW, $6.59 \pm 0.86 \mathrm{~kg}$ ) were randomly divided between treatments based on a $\mathrm{CRD}$ design according to initial BW. There were three treatments, eight replicates, and seven pigs. The treatments were as follows: basal diet without $\mathrm{ZnO}$ supplementation (control), 2,500 mg ZnO/ $\mathrm{kg}$ (In2500), $300 \mathrm{mg}$ nano-ZnO/kg (N300), and $150 \mathrm{mg}$ nano-ZnO/kg (N150). Experiment 2 was performed for 28 days and two phases (phase 1 , days 0 to 14 ; and phase 2, days 15 to 28).

\section{Preparation of nano $\mathrm{ZnO}$}

The HME technique was used to produce zinc oxide (TMC, Anyang, Korea). Zinc oxide, Span 80, Tween 80, and PEG 6000 were mixed at a 25:12:4:64 ratio. The processing procedure of the mixture (45 g/min) was performed using a hopper. The extruder had a twin screw (STS-25HS, Hankook E.M., Pyeongtaek, Korea) and a round-shaped die with a $1 \mathrm{~mm}$ diameter [18]. The temperatures of $55^{\circ} \mathrm{C}$ and $50^{\circ} \mathrm{C}$ were maintained in the barrel and die, respectively. The conveying and kneading were performed in the barrel at a speed of $0.025 \times \mathrm{g}$. The product was extruded through the die section and milled using an HBL-3500S grinder (Samyang Electronics, Gunpo, Korea) and transmission electron microscopy (TEM; JEM 1010, JEOL, Tokyo, Japan) was used to measure $\mathrm{ZnO}$ extrudate particle size. Powder of $\mathrm{ZnO}$ extrudate was dispersed in deionized water at $20 \mathrm{mg} / \mathrm{mL}$ and their particle properties were tested. The particle shape of $\mathrm{ZnO}$ extrudate was observed by TEM. The dispersed nanoparticles of $\mathrm{ZnO}$ were placed in the copper grid with film and dried for 10 min to be observed by TEM.

\section{Growth performance}

The BW gain was monitored during each phase by weighing on days 1, 14, and 28. At the end of each phase, the remaining feed in individual feeders was collected and weighed to determine the average daily gain $(\mathrm{ADG})$, feed conversion ratio (FCR), and average daily feed intake (ADFI).

\section{Microbial analyses}

An in vitro microbial test was performed to evaluate the antimicrobial effects of $\mathrm{ZnO}(0$, 300,500 , and 2,500 ppm) and nano- $\mathrm{ZnO}$ (300 and $500 \mathrm{ppm}$ ) mixed with nutrient broth, following the method of Joray et al. [24]. To test the antibacterial effects against Escherichia coli O157:H743895ATCC, Salmonella enteritidis ATCC 13076, and Listeria monocytogenes Scott A 19119 ATCC, $108 \mathrm{CFU} / \mathrm{mL}$ were mixed in the flasks. The inoculated broths were shaken at 120 rpm at $37^{\circ} \mathrm{C}$ for $24 \mathrm{~h}$, and samples were taken at h $3,6,9,12$, and 24 . The collected samples were serially diluted in sterile water and incubated on plate count agar. As per Hosseindoust et al. [12], fecal samples were collected on days 14 and 28 and sealed for microbiological analysis. The analysis was performed immediately after fecal collection. Lactobacillus spp. (de man, rogosa and sharp [MRS] agar + $0.200 \mathrm{~g} / \mathrm{L} \mathrm{NaN3}+0.500 \mathrm{~g} / \mathrm{L} \mathrm{L}$-cystine hydrochloride monohydrate), coliforms (violet red bile agar), and Clostridium spp. (tryptose sulfite cycloserine agar, Oxoid, Hampshire, UK) were counted. For microbial groups, anaerobic conditions were generated using a Gaspak anaerobic system (BBL, No. 260678, Difco, Detroit, MI, USA). CFUs were used to determine microbial populations and transformed into $\log 10$.

\section{Nutrient digestibility}

At the end of Phase 1 and Phase 2, the nutrient digestibility test was performed to determine the apparent digestibility of dry matter (DM), gross energy (GE), and crude protein (CP). The two selected pigs were placed in individual cages (one pig per cage) on day 7 in phase 1 and on day 28 in phase 2 to collect fecal samples. A $2.5 \mathrm{~g} \mathrm{~kg}^{-1}$ chromium oxide (indigestible marker) was added 
to the diet of the selected pigs. Fecal samples were collected from days 12 to 14 in phase 1 and from days 26 to 28 in phase 2 . The drying $\left(60^{\circ} \mathrm{C}, 72 \mathrm{~h}\right)$ process was performed directly after sample collection in a forced air-drying oven and then powdered with a mill (Thomas Model 4 Wiley Mill, Thomas Scientific, Swedesboro, NJ, USA) using a $1 \mathrm{~mm}$ screen. Diet and feces analyses of DM and $\mathrm{CP}$ were conducted using the AOAC [25] method. A bomb calorimeter (Model 1261, Parr Instrument, Moline, IL, USA) and a spectrophotometer (Jasco V-650, Jasco, Tokyo, Japan) were used to determine the $\mathrm{Cr}_{2} \mathrm{O}_{3}$ concentration.

The final calculation was performed with the following formula: Totalnutrient utilization (\%)= 100 - [100 - (Crinfeed (\%)Crinexcreta (\%) × Nutrientinexcreta (\%)Nutrientinfeed (\%))]

\section{Antioxidant status}

Six pigs close to the average weight were selected for each treatment for blood sampling via the jugular vein on days 14 and 28. The serum was harvested through centrifugation at 25,000×g for 15 min at $4^{\circ} \mathrm{C}$. The collected serum samples were frozen immediately at $-80^{\circ} \mathrm{C}$ for biochemical analyses. The antioxidant status of the serum and liver tissues was determined from the levels of superoxide dismutase (SOD), total antioxidant capacity (TAC), and glutathione peroxidase (GSHPx) using an ELISA microplate reader and assay kits (Cayman Chemical, Ann Arbor, MI, USA). All assays were conducted according to the manufacturer's instructions.

\section{Statistical analysis}

The data from the current experiment were statistically analyzed using SAS software (SAS Institute, Cary, NC, USA) and the general linear model (GLM) procedure. A CRD was used, and the pen was considered as the experimental unit for all parameters. Tukey's multiple range test was used for means separation at $p<0.05$.

\section{RESULTS}

\section{Particle size and growth performance}

The average particle size of nano- $\mathrm{ZnO}$ particles was $271.2 \pm 39 \mathrm{~nm}$ compared with $711.1 \pm 88$ $\mathrm{nm}$ for $\mathrm{ZnO}$. Experiment 1: The effects of dietary $\mathrm{ZnO}$ source and concentration are presented in Table 2. During phase 1, pigs in the N500 and IN2500 treatment groups showed higher ADG and ADFI than those in the control treatment group. There was no difference in FCR among treatment groups. Fecal score and diarrhea incidence were lower in the N500 and IN2500 treatment groups. In phase 2, there was no treatment effect on ADG, ADFI, FCR, and fecal score. However, there were significantly lower diarrhea incidences in the N500 and IN2500 treatment groups than in the control treatment. The overall result showed a greater ADG in pigs in the N500 and IN2500 treatment groups, and only the IN2500 treatment group showed a higher ADFI than the control treatment. The overall FCR was not affected by treatment. Experiment 2: During phase 1, pigs in the N300 treatment showed greater ADG and ADFI than those in the N150 treatment (Table 2). There was no difference in FCR among treatment groups. The fecal score was lower in the N300 and IN2500 treatment groups than in the N150 treatment group. In phase 2, there was no difference in $\mathrm{ADG}, \mathrm{ADFI}, \mathrm{FCR}$, and fecal scores among the treatment groups. The overall results showed no difference in ADG, ADFI, and FCR.

\section{In vitro microbial assay}

The in vitro effects of nano-sized $\mathrm{ZnO}$ and $\mathrm{ZnO}$ on targeted pathogens after 24-h exposure are 
Table 2. Effect of dietary zinc oxide of concentrations and sources on growth performance in weaning piglets

\begin{tabular}{|c|c|c|c|c|c|c|c|c|c|c|c|}
\hline \multirow{2}{*}{ Item } & \multicolumn{6}{|c|}{ Experiment 1} & \multicolumn{5}{|c|}{ Experiment 2} \\
\hline & Control & $\ln 2500$ & N500 & N150 & SEM & $p$-value & $\ln 2500$ & N300 & N150 & SEM & $p$-value \\
\hline \multicolumn{12}{|l|}{ Phase $1(0-14 d)$} \\
\hline ADG (g) & $195^{\mathrm{b}}$ & $242^{a}$ & $239^{a}$ & $203^{\mathrm{ab}}$ & 8.6 & 0.026 & $219^{a b}$ & $239^{a}$ & $196^{\mathrm{b}}$ & 7.19 & 0.028 \\
\hline ADFI $(g)$ & $304^{b}$ & $368^{a}$ & $362^{\mathrm{a}}$ & $322^{\mathrm{ab}}$ & 9.43 & 0.011 & 307 & 331 & 274.5 & 10.4 & 0.061 \\
\hline FCR & 1.56 & 1.52 & 1.51 & 1.60 & 0.02 & 0.644 & 1.40 & 1.39 & 1.39 & 0.02 & 0.941 \\
\hline Fecal score ${ }^{1)}$ & $3.87^{\mathrm{a}}$ & $3.13^{b}$ & $3.23^{b}$ & $3.53^{\mathrm{ab}}$ & 0.1 & 0.016 & $3.16^{b}$ & $3.13^{b}$ & $3.45^{\mathrm{a}}$ & 0.06 & 0.033 \\
\hline Diarrhea incidence $(\%)$ & $20.51^{\mathrm{a}}$ & $5.13^{\mathrm{b}}$ & $5.13^{b}$ & $10.26^{\mathrm{ab}}$ & 0.02 & 0.009 & & & & & \\
\hline \multicolumn{12}{|l|}{ Phase 2 (15-28 d) } \\
\hline ADG $(g)$ & 344 & 406 & 392 & 367 & 10.59 & 0.154 & 293 & 300 & 270 & 9.53 & 0.442 \\
\hline ADFI (g) & 528 & 562 & 500 & 486 & 16.94 & 0.442 & 438 & 442 & 400 & 8.58 & 0.065 \\
\hline FCR & 1.52 & 1.44 & 1.43 & 1.45 & 0.03 & 0.721 & 1.50 & 1.48 & 1.51 & 0.05 & 0.979 \\
\hline Fecal score ${ }^{1)}$ & 3.47 & 3.0 & 3.1 & 3.2 & 0.07 & 0.121 & 4.05 & 4.08 & 4.28 & 0.07 & 0.379 \\
\hline Diarrhea incidence $(\%)$ & $20.51^{\mathrm{a}}$ & $2.56^{b}$ & $5.13^{b}$ & $7.69^{\mathrm{ab}}$ & 2.56 & 0.011 & & & & & \\
\hline \multicolumn{12}{|l|}{ Overall $(0-28 d)$} \\
\hline ADG (g) & $270^{\mathrm{b}}$ & $324^{a}$ & $316^{a}$ & $285^{\mathrm{ab}}$ & 8.35 & 0.034 & 256 & 270 & 233 & 7.85 & 0.168 \\
\hline ADFI (g) & $4.12^{b}$ & $4.76^{\mathrm{a}}$ & $4.62^{\mathrm{ab}}$ & $4.26^{\mathrm{ab}}$ & 9.49 & 0.025 & 373 & 387 & 337 & 9.12 & 0.056 \\
\hline FCR & 1.53 & 1.47 & 1.46 & 1.50 & 0.01 & 0.396 & 1.45 & 1.435 & 1.45 & 0.036 & 0.961 \\
\hline
\end{tabular}

1) $1=$ hard, dry pellets in a small, hard mass; 2 = hard, formed stool that remains firm and soft; $3=$ soft, formed and moist stool that retains its shape; $4=$ soft, unformed stool that assumes the shape of the container; $5=$ watery, liquid stool that can be poured.

${ }^{a, b}$ Means within a column with different superscripts differ significantly $(p<0.05)$.

$A D G$, average daily gain; ADFI, average daily feed intake; FCR, feed conversion ratio.

presented in Fig. 1. Listeria monocytogenes growth was inhibited when exposed to 300 and 500 ppm of $\mathrm{ZnO}$ from h 3 to h 24 of incubation. Moreover, the population of Listeria monocytogenes in the N500 and N300 treatment groups decreased linearly from h 0 to h 24 . The same trend was observed after incubation with $\mathrm{ZnO}$ and $E$. coli. There was a significant increase in the number of E. coli in the N500 and N300 treatment groups throughout the 24-h experiment. The population of Salmonella typhimurium varied slightly among the treatment groups, and significant differences were observed at $\mathrm{h} 9$ with a lower population in the N500 treatment group and the lower populations in the N500 and N300 treatment groups at h 12 and 24.

\section{Fecal microbiota}

Experiment 1: The effects of $\mathrm{ZnO}$ concentration and source on intestinal microbiota are presented in Table 3. In phase 1, there was no difference in the number of Lactobacillus spp. However, the colonization of coliforms $(p<0.05)$ and Clostridium spp. $(p<0.01)$ significantly decreased in pigs fed the N500 and IN2500 diets compared with those fed the control diet. During phase 2, the number of Lactobacillus spp. and coliforms did not change among the treatment groups. The IN2500 pigs showed lower $(p<0.05)$ counts of Clostridium spp. than the N150 and control treatment groups. Moreover, there were lower $(p<0.05)$ populations of Clostridium spp. in the N500 and N150 treatment groups than in the control treatment group. Experiment 2: In phase 1, there was no difference in the number of Lactobacillus spp. However, the colonization of coliforms $(p<$ $0.05)$ and Clostridium spp. $(p<0.05)$ decreased in pigs fed the N300 diet compared with those fed the N150 diet (Table 3). During phase 2, the treatments did not affect the number of Lactobacillus spp. and coliforms. The N300 pigs showed lower $(p<0.05)$ counts of Clostridium spp. than the N150 pigs. There was no difference in the colonization of Clostridium spp. between the IN2500 and N150 treatment groups. 

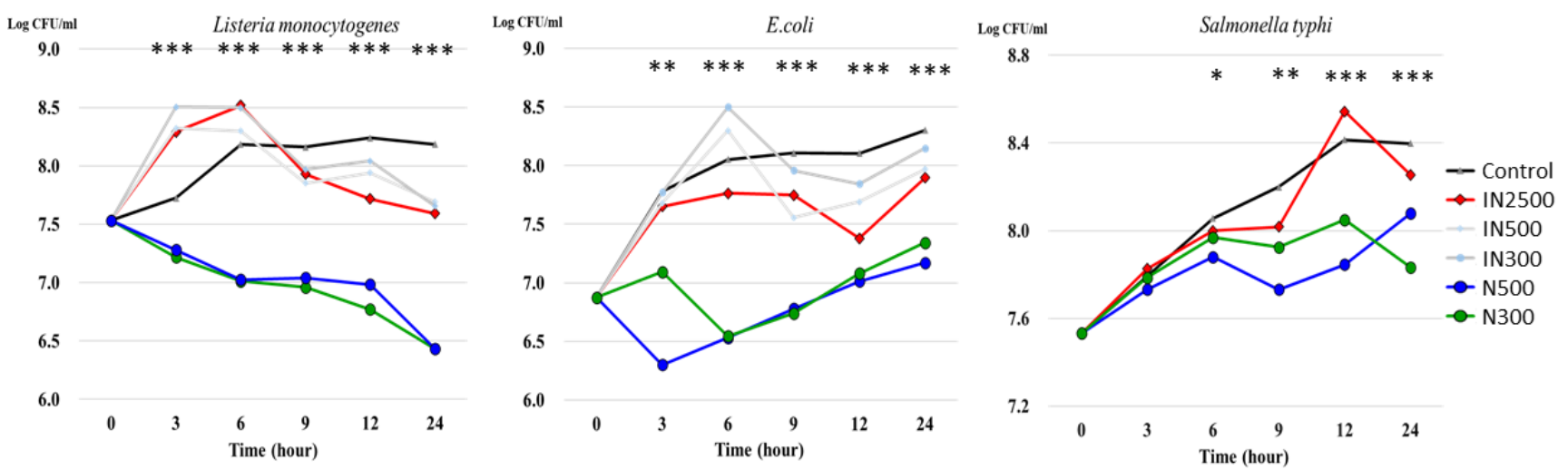

Fig. 1. Antibacterial effects of $\mathrm{ZnO}$ source and concentration on Listeria monocytogenes, Escherichia coli, and Salmonella Typhimurium. control, basal diet; IN2500, basal diet + 2,500 ppm ZnO; IN500, basal diet + 500 ppm ZnO; IN300, basal diet + 300 ppm ZnO; N150, basal diet + 150 ppm nano ZnO; N300, basal diet $+300 \mathrm{ppm}$ nano $\mathrm{ZnO} ;{ }^{*} p<0.05 ;{ }^{* *} p<0.01 ;{ }^{* * *} p<0.001$.

Table 3. Effect of dietary zinc oxide of concentrations and sources on growth performance in weaning piglets

\begin{tabular}{|c|c|c|c|c|c|c|c|c|c|c|c|}
\hline \multirow{2}{*}{ Item } & \multicolumn{6}{|c|}{ Experiment 1} & \multicolumn{5}{|c|}{ Experiment 2} \\
\hline & Control & $\ln 2500$ & N500 & N150 & SEM & $p$-value & $\ln 2500$ & N300 & N150 & SEM & $p$-value \\
\hline \multicolumn{12}{|l|}{ Phase 1 (d 14) } \\
\hline Lactobacillus spp. & 9.29 & 9.47 & 9.58 & 9.33 & 0.08 & 0.616 & 9.58 & 9.62 & 9.65 & 0.05 & 0.836 \\
\hline Coliforms & $8.72^{\mathrm{a}}$ & $8.34^{b}$ & $8.32^{b}$ & $8.65^{\mathrm{ab}}$ & 0.06 & 0.015 & $8.67^{\mathrm{ab}}$ & $8.54^{b}$ & $8.79^{a}$ & 0.06 & 0.023 \\
\hline Clostridium spp. & $8.71^{\mathrm{a}}$ & $8.26^{b}$ & $8.37^{b}$ & $8.54^{\mathrm{ab}}$ & 0.06 & 0.008 & $8.56^{\mathrm{ab}}$ & $8.41^{b}$ & $8.80^{a}$ & 0.06 & 0.023 \\
\hline \multicolumn{12}{|l|}{ Phase 2 (d 28) } \\
\hline Lactobacillus spp. & 9.64 & 9.56 & 9.62 & 9.58 & 0.07 & 0.986 & 9.53 & 9.68 & 9.75 & 0,05 & 0.169 \\
\hline Coliforms & 8.57 & 8.48 & 8.45 & 8.54 & 0.03 & 0.433 & 8.59 & 8.47 & 8.66 & 0.07 & 0.623 \\
\hline Clostridium spp. & $8.76^{\mathrm{a}}$ & $8.55^{\mathrm{b}}$ & $8.60^{\mathrm{ab}}$ & $8.65^{\mathrm{a}}$ & 0.03 & 0.015 & $8.67^{\mathrm{ab}}$ & $8.47^{b}$ & $8.74^{\mathrm{a}}$ & 0.04 & 0.013 \\
\hline
\end{tabular}

${ }_{\mathrm{a}, \mathrm{b}}$ Means within a column with different superscripts differ significantly $(p<0.05)$.

\section{Antioxidant capacity}

The effects of dietary $\mathrm{ZnO}$ source and concentration on antioxidant capacity are shown in Fig. 2. In phases 1 and 2, the total plasma antioxidant capacity was greater in the IN2500 and N500 treatments than in the control $(p<0.05)$. In phase 1 , the superoxide dismutase activity was greater in pigs fed the IN2500 diet than those fed the control diet. In phase 2, the IN2500 and N500 treatment groups showed a greater SOD activity than the control and N150 treatments. There was no difference in the activity of GSH-Px in either phase.

\section{Nutrient digestibility}

Experiment 1: The effects of $\mathrm{ZnO}$ on nutrient digestibility are presented in Table 4. There was no difference in the digestibility of DM, CP, ether extract (EE), and GE in phase 1. In phase 2, there was no difference in digestibility of DM, EE, and GE. However, the digestibility of CP was greater $(p<0.05)$ in pigs fed the IN2500 and N500 diets compared with the control treatment. Experiment 2: There was no difference in the digestibility of DM, CP, EE, and GE in phase 1 (Table 4). In phase 2 , there was no difference in the digestibility of DM, EE, and GE. 
A

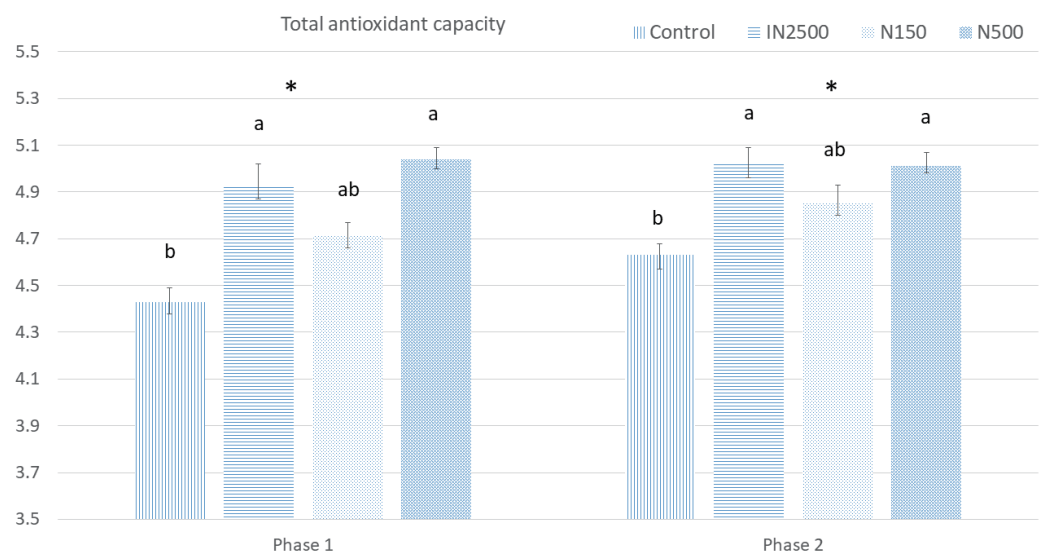

B

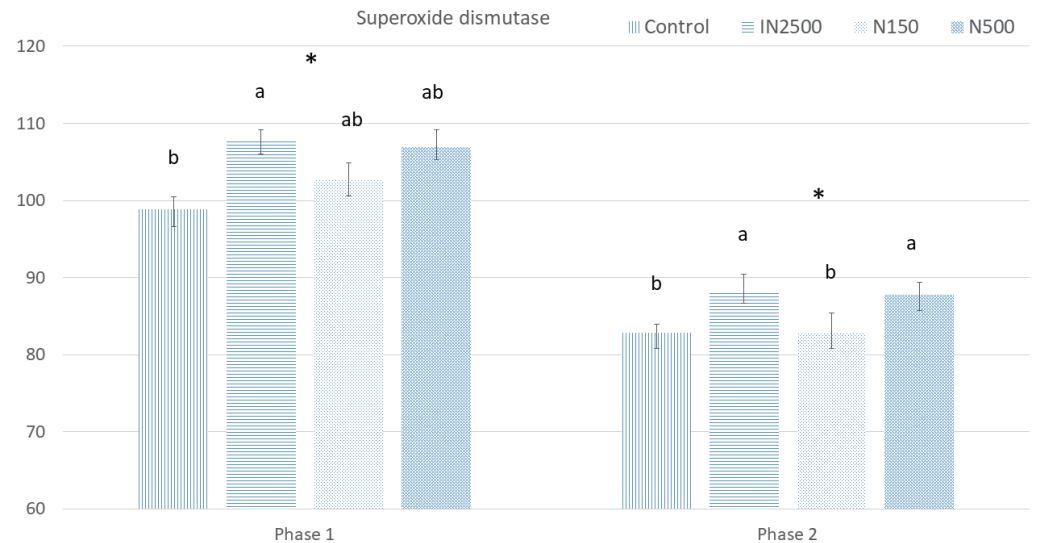

C

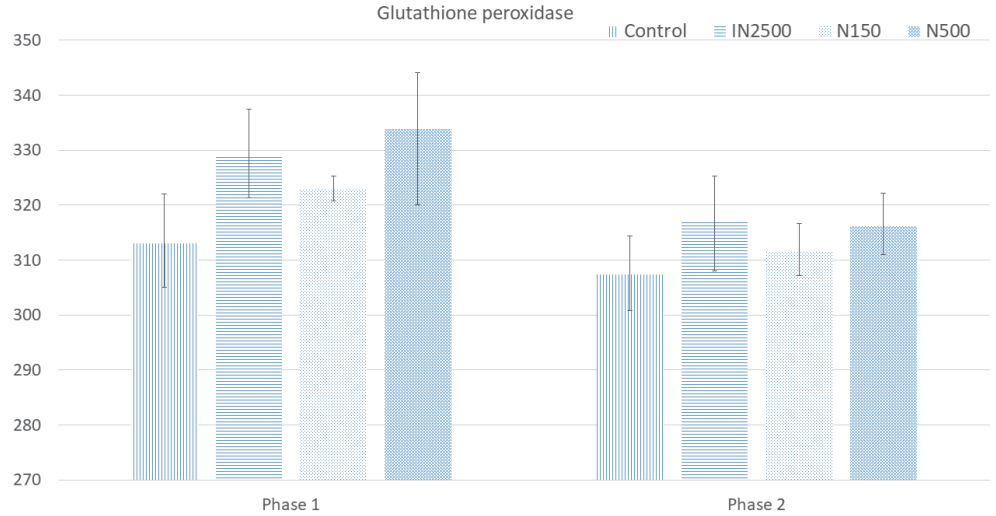

Fig. 2. Effect of $\mathrm{ZnO}$ source and concentration on concentration of total antioxidant capacity (a), superoxide dismutase (b), glutathione peroxidase (c) in the serum of weaned pigs. Control, basal diet; IN2500, basal diet + 2,500 ppm ZnO; N150, basal diet + 150 ppm nano ZnO; N300, basal diet +300 ppm nano $\mathrm{ZnO} ;{ }^{*} p<0.05 ;{ }^{* *} p<0.01 ;{ }^{* * *} p<0.001$.

\section{DISCUSSION}

In the current study, the improvement of $\mathrm{ADG}$ in the first phase emphasizes the benefits of $\mathrm{ZnO}$ supplements during the early weaning compared to supplementation from 2 weeks onward. The first week after weaning is critical in the pig's life due to the change of diet from milk to solid form $[11,14]$. Additionally, the insignificant difference between the In2500 treatment and N300 or 
Table 4. Effect of dietary zinc oxide of concentrations and sources on nutrient digestibility in weaning piglets (\%)

\begin{tabular}{|c|c|c|c|c|c|c|c|c|c|c|c|}
\hline \multirow{2}{*}{ Item } & \multicolumn{6}{|c|}{ Experiment 1} & \multicolumn{5}{|c|}{ Experiment 2} \\
\hline & Control & $\ln 2500$ & N500 & N150 & SEM & $p$-value & $\ln 2500$ & N300 & N150 & SEM & $p$-value \\
\hline \multicolumn{12}{|l|}{ Phase 1 (d 14) } \\
\hline $\mathrm{CP}$ & 77.84 & 80.47 & 79.25 & 78.76 & 0.41 & 0.119 & 78.23 & 78.41 & 77.63 & 0.26 & 0.468 \\
\hline EE & 72.21 & 73.27 & 73.04 & 72.61 & 0.19 & 0.697 & & & & & \\
\hline DM & 78.18 & 80.35 & 80.25 & 79.19 & 0.37 & 0.108 & 79.57 & 79.29 & 79.05 & 0.27 & 0.771 \\
\hline $\mathrm{CP}$ & $75.56^{\mathrm{b}}$ & $78.90^{\mathrm{a}}$ & $78.63^{\mathrm{a}}$ & $76.94^{\mathrm{ab}}$ & 0.52 & 0.042 & 77.2 & 77.69 & 76.58 & 0.29 & 0.324 \\
\hline EE & 71.6 & 72.13 & 71.93 & 71.91 & 0.16 & 0.759 & & & & & \\
\hline GE & 80.91 & 81.88 & 81.97 & 81.16 & 0.34 & 0.678 & 82.07 & 82.13 & 81.3 & 0.36 & 0.626 \\
\hline
\end{tabular}

${ }^{a, b}$ Means within a column with different superscripts differ significantly $(p<0.05)$.

DM, dry matter; CP, crude protein; EE, ether extract; GE, gross energy.

N500 treatment groups shows that a low level of nano- $\mathrm{ZnO}$ is a better option than a high level of regular $\mathrm{ZnO}$. The positive influence of $\mathrm{ZnO}$ on $\mathrm{ADG}$ in this study is in agreement with previous reports where supplementation with $\mathrm{ZnO}$ as regular $[4,9,11,26]$ or nano $[13,19]$ forms increased ADG in pigs. The reduction in the number of pathogenic bacteria, including E. coli and Clostridium spp., may be associated with an increase in growth rate. It has been confirmed that supplementing with 2,500 ppm $\mathrm{ZnO}$ improved the growth rate of weanling pigs [11,27,28], whereas a lower dietary supplementation of $\mathrm{ZnO}$ has not been beneficial [29]. Several studies have reported using pharmacological $\mathrm{ZnO}[2,12,30]$ or nano- $\mathrm{ZnO}$ [8], without any significant effect on the growth performance of weaned pigs. Apart from dietary $\mathrm{ZnO}$ levels, particle size can be a determinant factor in the effectiveness of pathogenic control. The use of a proper nano method may govern the effectiveness of $\mathrm{ZnO}$ nanoparticles, as the aggregation of nanoparticles decreases the efficiency of the digestion process. Furthermore, the improved antioxidant status could also explain the increased overall ADG. Zinc is an important anti-stress mineral, and its antioxidant role in improving growth performance can be explained by its contribution to the production of antioxidant enzymes, including GSH-Px and SOD [4,20,31]. Weaning stress increases lipid peroxidation and consequently decreases glutathione peroxidase activity [15,31]. Therefore, the antioxidant role of $\mathrm{Zn}$ increases its requirement after weaning, compared to the other stages.

Using non-antibiotic supplements to decrease intestinal pathogen colonization is an effective approach to increase gut health and growth performance of weaned pigs. Among the options, $\mathrm{ZnO}$ is still one of the most important [11,14]. Recently, nanoparticles have received increasing attention because of their ability to be used at lower doses [19]. However, previous studies have shown that a 2,500 $\mathrm{mg} \mathrm{ZnO} / \mathrm{kg}$ feed has to be added to the weaned pigs' diet to reduce diarrhea incidences $[12,15]$, and lower doses of nano- $\mathrm{ZnO}$ are not adequate to control diarrhea [30]. This is in contrast with our results. The health of pigs during the transition period (i.e., from milk to a solid diet) can be determined by the frequency of diarrhea incidences $[6,8]$. The inability of the intestine to absorb essential nutrients increases the opportunity for pathogen growth, which may be the main cause of diarrhea in weaned pigs $[8,13,14]$. The reduction of diarrhea incidences and fecal scores in the In2500 and N500 treatment groups confirmed the positive effects of high $\mathrm{ZnO}$ supplementation in the diet to maintain gastrointestinal tract health in weaned pigs $[8,12,19]$. In the current study, the decrease in E. coli and Clostridium spp. suggests that the antibacterial role of $\mathrm{ZnO}$ protects the intestine from pathogenic damage, which is indicated by the decreased fecal scores and diarrhea 
incidences. E. coli is one of the most common bacteria that triggers diarrhea incidences in piglets during the post-weaning period [13,19,32]. Additionally, Clostridium spp. is opportunistic bacteria that spread via the fecal-oral route and produces several cytotoxins, which increase inflammation and diarrhea by binding to epithelial cell receptors $[33,34]$. These toxins damage the tight junctions, allowing the toxins to leak into enterocytes [34], and could be responsible for diarrhea incidences in weaned piglets. Supplementation of $\mathrm{ZnO}$ at a dose of $2,500 \mathrm{mg} / \mathrm{kg}$ diet or nano- $\mathrm{ZnO}$ at a dose of $300 \mathrm{~g} / \mathrm{kg}$ diet was beneficial in controlling post-weaning diarrhea and $E$. coli colonization.

The improvement in the apparent total tract digestibility (ATTD) of CP was in line with the study of Oh et al. [19] and Lee et al. [11], who reported increased CP digestibility in weaned pigs fed a pharmacological dose of $\mathrm{ZnO}$. The increased CP digestibility in the IN2500 and N500 treatment groups might be associated with the manipulation of gut microflora, which resulted in lower colonization by Clostridium spp. and E. coli. Previous studies reported that increased villus height in the intestine [19] and decreased $E$. coli populations were responsible for improving $\mathrm{CP}$ digestibility in weaned pigs fed $\mathrm{ZnO}$. Suppression of pathogenic intestinal microbiota and increased antioxidant levels may further improve gut integrity to utilize more nutrients.

Several environmental and physiological factors affect intestinal development in neonates. In a healthy system, digestive enzymes hydrolyze the nutrients along the small intestine. The undigested nutrients flow to the large intestine and stimulate fermentation by anaerobic bacteria [5]. The current study showed that the population of gut-friendly bacteria such as Lactobacillus spp. was unaffected by the treatments. Simultaneously, the colonization of coliforms and Clostridium spp. were reduced in the In2500, N500, and N300 groups. Previous studies reported that a high dose of $\mathrm{ZnO}$ in weaned pig diets reduced the population of Clostridium spp. and coliforms [11,19] and increased the population of Lactobacillus spp. [11]. They stated that the increase in the Lactobacillus spp. population is likely due to the decreased colonization of E. coli and Clostridium spp. and the increased opportunity to proliferate in a less competitive environment [11]. Supplementation with $\mathrm{ZnO}$ increases hydrogen peroxide production and subsequently decreases the $\mathrm{pH}$ of the intestinal lumen [35]. The proliferation of E. coli and Clostridium spp. can be controlled by an acidic environment, while Lactobacillus spp. can tolerate an acidic milieu [36]. In contrast, several studies have shown no anti-pathogenic effects when using pharmacological doses of $\mathrm{ZnO}$ [12]. The environmental and physiological conditions of weaned pigs may affect the efficiency of dietary $\mathrm{ZnO}$. Moreover, using 50, 150, 250, and 1,000 $\mathrm{mg} \mathrm{ZnO} / \mathrm{kg}$ in weaned pigs did not affect the number of clostridial clusters, while supplementation with $2,500 \mathrm{mg} \mathrm{ZnO} / \mathrm{kg}$ significantly reduced the Clostridium spp. population [19,37]. Therefore, doses lower than 2,500 $\mathrm{mg} \mathrm{ZnO/kg}$ cannot be recommended unless nano- $\mathrm{ZnO}$ is used because the decreased particle size increases the antibacterial efficiency of $\mathrm{ZnO}[19,38]$. The nano-sized particles have a higher surface area, which increases the active surface compared to the regular particles [27,30,39]. Therefore, it can be presumed that nano- $\mathrm{ZnO}$ at lower doses is as effective as pharmacological doses of $\mathrm{ZnO}$ in preventing pathogen colonization.

The decrease in the production of antioxidant enzymes during weaning stress increases intestinal oxidative injury $[4,26]$. The enzymes, including SOD and GSH-Px, are essential for alleviating the overproduction of free radicals during stress [39,40]. It has been shown that supplementation with 3,000 $\mathrm{mg} \mathrm{ZnO} / \mathrm{kg}$ restored the plasma antioxidant capacity of weanling pigs by increasing SOD and GSH-Px activities and reducing Malondialdehyde (MDA) [26]; however, they reported no change in GSH-Px activity. Although the increased activity of SOD in the plasma was in line with the TAC, the GSH-Px activity was not affected in the current study. Zinc contributes to the production of several antioxidant enzymes and the regulation of the redox status by reducing the ratio of oxidized glutathione to reduced glutathione, which reduces apoptosis in the small intestine 
[41]. SOD plays an important role in protecting cells from exposure to reactive oxygen species during stress [4]. In this study, increased TAC in the plasma of pigs treated with In2500 and N500 may be related to the higher activity of SOD that increases the potential of scavenging free radicals, lipid peroxides, and hydroperoxide control [39]. This preserves the antioxidant factors and increases the TAC. Several studies have reported that SOD production can be compromised under stressful conditions [4]. These results suggest that dietary supplementation of nano- $\mathrm{ZnO}$ at $500 \mathrm{ppm}$ can be as beneficial to the antioxidant status of weanling piglets as supplementation with 3,000 ppm $\mathrm{ZnO}$.

\section{CONCLUSION}

Compared with the control treatment, the N500 diet increased growth performance. Additionally, it decreased the fecal scores and coliform and Clostridium spp. populations in weanling pigs. The N300 diet showed a growth performance comparable to the In2500 treatment, while the N150 treatment showed a compromised growth performance and intestinal microbiota. The present data suggest that using nano- $\mathrm{ZnO}$ in doses ranging from 300 to $500 \mathrm{ppm}$ can be beneficial.

\section{REFERENCES}

1. Lallès JP, Bosi P, Smidt H, Stokes CR. Weaning: a challenge to gut physiologists. Livest Sci. 2007;108:82-93. https://doi.org/10.1016/j.livsci.2007.01.091

2. Mazzoni M, Merialdi G, Sarli G, Trevisi P, Bosi P. Effect of two doses of different zinc sources (inorganic vs. chelated form) on the epithelial proliferative activity and the apoptotic index of intestinal mucosa of early-weaned pigs orally challenged with E. coli K88. Asian-Australas J Anim Sci. 2010;23:777-85. https://doi.org/10.5713/ajas.2010.90352

3. Moturi J, Kim KY, Hosseindoust A, Lee JH, Xuan B, Park J, et al. Effects of Lactobacillus salivarius isolated from feces of fast-growing pigs on intestinal microbiota and morphology of suckling piglets. Sci Rep. 2021;11:6757. https://doi.org/10.1038/s41598-021-85630-7

4. Jiao LF, Zhang QH, Wu H, Wang CC, Cao ST, Feng J, et al. Influences of copper/zincloaded montmorillonite on growth performance, mineral retention, intestinal morphology, mucosa antioxidant capacity, and cytokine contents in weaned piglets. Biol Trace Elem Res. 2018;185:356-63. https://doi.org/10.1007/s12011-018-1259-4

5. Hosseindoust AR, Lee SH, Kim JS, Choi YH, Kwon IK, Chae BJ. Productive performance of weanling piglets was improved by administration of a mixture of bacteriophages, targeted to control Coliforms and Clostridium spp. shedding in a challenging environment. J Anim Physiol Anim Nutr. 2017;101:e98-107. https://doi.org/10.1111/jpn.12567

6. Jeong YD, Ko HS, Hosseindoust A, Choi YH, Chae BJ, Yu DJ, et al. Lactobacillus-based fermentation product and lactose level in the feed for weanling pigs: effects on intestinal morphology, microbiota, gas emission, and targeted intestinal coliforms. Livest Sci. 2019;227:90-6. https://doi.org/10.1016/j.livsci.2019.06.018

7. Lallès JP, Bosi P, Smidt H, Stokes CR. Nutritional management of gut health in pigs around weaning. Proc Nutr Soc. 2007;66:260-8. https://doi.org/10.1017/S0029665107005484

8. Xia T, Lai W, Han M, Han M, Ma X, Zhang L. Dietary ZnO nanoparticles alters intestinal microbiota and inflammation response in weaned piglets. Oncotarget. 2017;8:64878-91. https://doi.org/10.18632/oncotarget.17612

9. Byun YJ, Lee CY, Kim MH, Jung DY, Han JH, Jang I, et al. Effects of dietary supplementation of a lipid-coated zinc oxide product on the fecal consistency, growth, and morphology of the intestinal mucosa of weanling pigs. J Anim Sci Technol. 2017;59:29. https://doi.org/10.1186/ 
s40781-017-0159-z

10. Han YK, Thacker PA. Effects of antibiotics, zinc oxide or a rare earth mineral-yeast product on performance, nutrient digestibility and serum parameters in weanling pigs. Asian-Australas J Anim Sci. 2010;23:1057-65. https://doi.org/10.5713/ajas.2010.90569

11. Lee S, Hosseindoust A, Goel A, Choi Y, Kwon IK, Chae B. Effects of dietary supplementation of bacteriophage with or without zinc oxide on the performance and gut development of weanling pigs. Ital J Anim Sci. 2016;15:412-8. https://doi.org/10.1080/182805 1X.2016.1188676

12. Hosseindoust AR, Lee SH, Kim JS, Choi YH, Noh HS, Lee JH, et al. Dietary bacteriophages as an alternative for zinc oxide or organic acids to control diarrhoea and improve the performance of weanling piglets. Vet Med. 2017;62:53-61. https://doi.org/10.17221/7/2016VETMED

13. Pei X, Xiao Z, Liu L, Wang G, Tao W, Wang M, et al. Effects of dietary zinc oxide nanoparticles supplementation on growth performance, zinc status, intestinal morphology, microflora population, and immune response in weaned pigs. J Sci Food Agric. 2019;99:136674. https://doi.org/10.1002/jsfa.9312

14. Sales J. Effects of pharmacological concentrations of dietary zinc oxide on growth of postweaning pigs: a meta-analysis. Biol Trace Elem Res. 2013;152:343-9. https://doi.org/10.1007/ s12011-013-9638-3

15. Bonetti A, Tugnoli B, Piva A, Grilli E. Towards zero zinc oxide: feeding strategies to manage post-weaning diarrhea in piglets. Animals. 2021;11:642. https://doi.org/10.3390/ani11030642

16. Kim M, Hosseindoust A, Choi Y, Lee J, Kim K, Kim T, et al. Effects of hot-melt extruded nano-copper as an alternative for the pharmacological dose of copper sulfate in weanling pigs. Biol Trace Elem Res. 2021;199: 2925-35. https://doi.org/10.1007/s12011-020-02426-y

17. Kim K, Hosseindoust A, Choi Y, Kim M, Lee J, Kim T, et al. Hot-melt extruded selenium: a highly absorbable nano-selenium in lactating sows exposed to high ambient temperature. Biol Trace Elem Res. 2021;199:3345-53. https://doi.org/10.1007/s12011-020-02459-3

18. Lee SY, Nam S, Choi Y, Kim M, Koo JS, Chae BJ, et al. Fabrication and characterizations of hot-melt extruded nanocomposites based on zinc sulfate monohydrate and soluplus. Appl Sci. 2017;7:902. https://doi.org/10.3390/app7090902

19. Oh SM, Kim MJ, Hosseindoust A, Kim KY, Choi YH, Ham HB, et al. Hot melt extrudedbased nano zinc as an alternative to the pharmacological dose of $\mathrm{ZnO}$ in weanling piglets. Asian-Australas J Anim Sci. 2020;33:992-1001. https://doi.org/10.5713/ajas.19.0140

20. Lee J, Hosseindoust A, Kim K, Kim T, Mun J, Chae B, et al. Improved growth performance, antioxidant status, digestive enzymes, nutrient digestibility and zinc bioavailability of broiler chickens with nano-sized hot-melt extruded zinc sulfate. Biol Trace Elem Res. 2022;200:132130. https://doi.org/10.1007/s12011-021-02747-6

21. Lee J, Hosseindoust A, Kim M, Kim K, Choi Y, Moturi J, et al. Effects of hot melt extrusion processed nano-iron on growth performance, blood composition, and iron bioavailability in weanling pigs. J Anim Sci Technol. 2019;61:216-24. https://doi.org/10.5187/jast.2019.61.4.216

22. Lee J, Hosseindoust A, Kim M, Kim K, Choi Y, Lee S, et al. Biological evaluation of hotmelt extruded nano-selenium and the role of selenium on the expression profiles of seleniumdependent antioxidant enzymes in chickens. Biol Trace Elem Res. 2020;194:536-44. https:// doi.org/10.1007/s12011-019-01801-8

23. National Research Council. Nutrient requirements of swine. 11th rev ed. Washington, DC: National Academy Press; 2012.

24. Joray MB, del Rollán MR, Ruiz GM, Palacios SM, Carpinella MC. Antibacterial activity of 
extracts from plants of central Argentina-isolation of an active principle from Achyrocline satureioides. Planta Med. 2011;77:95-100. https://doi.org/10.1055/s-0030-1250133

25. AOAC [Association of Official Analytical Chemists] International. Official methods of analysis of AOAC International. 18th ed. Gaithersburg, MD: AOAC International; 2007.

26. Zhu C, Lv H, Chen Z, Wang L, Wu X, Chen Z, et al. Dietary zinc oxide modulates antioxidant capacity, small intestine development, and jejunal gene expression in weaned piglets. Biol Trace Elem Res. 2017;175:331-8. https://doi.org/10.1007/s12011-016-0767-3

27. Kim MJ, Shim YH, Choi YH, Kim KY, Hosseindoust A, Lee SY, et al. Effects of supplementation of hot melt extrusion processed zinc sulfate on growth performance, nutrients digestibility, small intestinal morphology and excretion of zinc in weanling pigs. Ann Anim Resour Sci. 2017;28:169-79. https://doi.org/10.12718/AARS.2017.28.4.169

28. Walk CL, Wilcock P, Magowan E. Evaluation of the effects of pharmacological zinc oxide and phosphorus source on weaned piglet growth performance, plasma minerals and mineral digestibility. Animal. 2015;9:1145-52. https://doi.org/10.1017/S175173111500035X

29. Poulsen HD, Larsen T. Zinc excretion and retention in growing pigs fed increasing levels of zinc oxide. Livest Prod Sci. 1995;43:235-42. https://doi.org/10.1016/0301-6226(95)00039-N

30. Milani NC, Sbardella M, Ikeda NY, Arno A, Mascarenhas BC, Miyada VS. Dietary zinc oxide nanoparticles as growth promoter for weanling pigs. Anim Feed Sci Technol. 2017;227:13-23. https://doi.org/10.1016/j.anifeedsci.2017.03.001

31. Swain PS, Rao SBN, Rajendran D, Dominic G, Selvaraju S. Nano zinc, an alternative to conventional zinc as animal feed supplement: a review. Anim Nutr. 2016;2:134-41. https://doi. org/10.1016/j.aninu.2016.06.003

32. Melin L, Mattsson S, Katouli M, Wallgren P. Development of post-weaning diarrhoea in piglets. Relation to presence of Escherichia coli strains and rotavirus.J Vet Med B. 2004;51:1222. https://doi.org/10.1111/j.1439-0450.2003.00723.x

33. Kim JS, Hosseindoust A, Lee SH, Choi YH, Kim MJ, Lee JH, et al. Bacteriophage cocktail and multi-strain probiotics in the feed for weanling pigs: effects on intestine morphology and targeted intestinal coliforms and Clostridium. Animal. 2017;11:45-53. https://doi.org/10.1017/ S1751731116001166

34. Hookman P, Barkin JS. Clostridium difficile associated infection, diarrhea and colitis. World J Gastroenterol. 2009;15:1554-80. https://doi.org/10.3748/wjg.15.1554

35. Sawai J, Shoji S, Igarashi H, Hashimoto A, Kokugan T, Shimizu M, et al. Hydrogen peroxide as an antibacterial factor in zinc oxide powder slurry. J Ferment Bioeng. 1998;86:521-2. https:// doi.org/10.1016/S0922-338X(98)80165-7

36. Heo JM, Opapeju FO, Pluske JR, Kim JC, Hampson DJ, Nyachoti CM. Gastrointestinal health and function in weaned pigs: a review of feeding strategies to control post-weaning diarrhoea without using in-feed antimicrobial compounds. J Anim Physiol Anim Nutr. 2013;97:207-37. https://doi.org/10.1111/j.1439-0396.2012.01284.x

37. Pieper R, Vahjen W, Neumann K, Van Kessel AG, Zentek J. Dose-dependent effects of dietary zinc oxide on bacterial communities and metabolic profiles in the ileum of weaned pigs. J Anim Physiol Anim Nutr. 2012;96:825-33. https://doi.org/10.1111/j.1439-0396.2011.01231.x

38. Yamamoto O. Influence of particle size on the antibacterial activity of zinc oxide. Int J Inorg Mater. 2001;3:643-6. https://doi.org/10.1016/S1466-6049(01)00197-0

39. Hosseindoust A, Oh SM, Ko HS, Jeon SM, Ha SH, Jang A, et al. Muscle antioxidant activity and meat quality are altered by supplementation of astaxanthin in broilers exposed to high temperature. Antioxidants. 2020;9:1032. https://doi.org/10.3390/antiox9111032

40. Ha SH, Kang HK, Hosseindoust A, Mun JY, Moturi J, Tajudeen H, et al. Effects of scopoletin 
supplementation and stocking density on growth performance, antioxidant activity, and meat quality of Korean native broiler chickens. Foods. 2021;10:1505. https://doi.org/10.3390/ foods10071505

41. Wang X, Ou D, Yin J, Wu G, Wang J. Proteomic analysis reveals altered expression of proteins related to glutathione metabolism and apoptosis in the small intestine of zinc oxide-supplemented piglets. Amino Acids. 2009;37:209-18. https://doi.org/10.1007/s00726-009-0242-y 